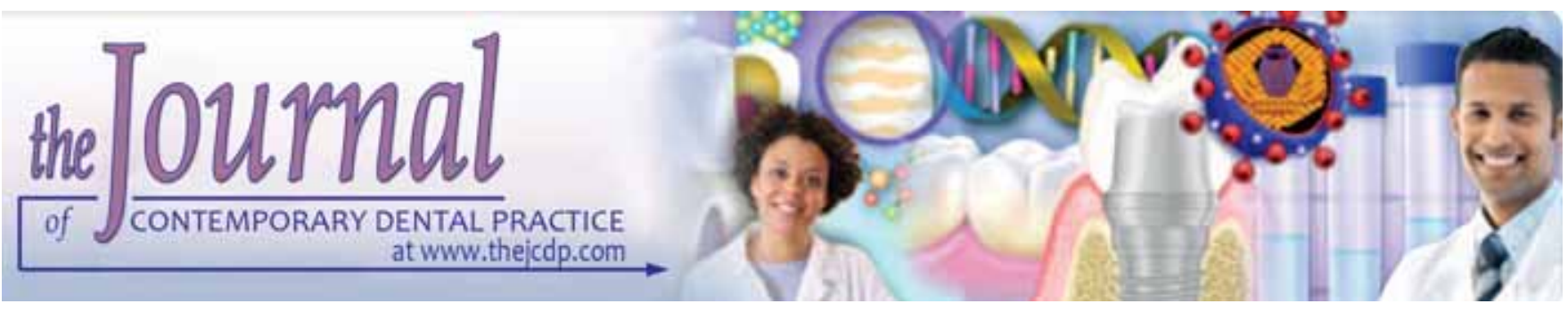

\title{
Relationship between Impacts of Complete Denture Treatment on Daily Living, Satisfaction and Personality Profiles
}

Raed O Abu Hantash, Mahmoud K AL-Omiri, Mohammad Abu Yunis, Najla Dar-Odeh, Edward Lynch

\begin{abstract}
Objectives: To investigate the association between satisfaction with conventional complete denture prostheses (CDs), impacts of CDs on daily living and personality profiles.

Materials and methods: Fifty-six patients (28 males and 28 females; mean age $53.79 \pm 7.762$ years) with fitted upper and lower removable CDs were recruited for this study. Clinical success of CDs was assessed according to specific clinical criteria. The dental impact on daily living questionnaire (DIDL) was used to measure satisfaction with CDs and their impacts on daily living. NEO five factor inventory (NEO - FFI) was used to measure patients' personality profiles. Pearson correlation test and regression models were used to analyze the collected data.
\end{abstract}

Results: Females were more satisfied with appearance and less satisfied with eating and scored higher on neuroticism, and lower on extraversion and openness personality domains $(p<0.05)$. Older patients were more satisfied with appearance and less satisfied with oral comfort and general performance $(p<0.05)$. Neuroticism, extraversion, openness and agreeableness personality profiles could predict and had significant relationship with CDs impacts on daily living and satisfaction with CDs.

Conclusion: Psychological profiles (e.g. neuroticism, extraversion, openness and agreeableness) might play a role and explain CDs impacts on daily living and patients' satisfaction with their oral status and CD treatment, therefore, might be used to predict satisfactory outcomes of CD treatment. In this regard, technical aspects of CDs are less essential when the prosthesis is clinically successful.

Clinical significance: Psychological factors may play a role and also provide valuable information for the prediction of satisfactory outcomes of complete denture treatment.

Keywords: Complete denture impacts on daily living (DIDL), NEO-FFI, Personality, Satisfaction.

How to cite this article: Hantash ROA, AL-Omiri MK, Yunis MA, Dar-Odeh N, Lynch E. Relationship between Impacts of Complete Denture Treatment on Daily Living, Satisfaction and Personality Profiles. J Contemp Dent Pract 2011;12(3):200-207.
Source of support: Nil

Conflict of interest: None declared

\section{INTRODUCTION}

Although conventional complete denture therapy is not considered the minimum standard of treatment for total edentulism in some developed countries; it is still extensively used for the replacement of missing dentition and the use of it is not expected to decline in the near future especially in less developed populations with limited economic resources. ${ }^{1}$ Therefore, advancements in conventional denture therapy are still in demand and should be researched and improved. However, little attention has been paid to the psychosocial impacts of such treatment.

Conventional complete dentures improve patients' satisfaction and quality of life. ${ }^{2,3}$ This is still valid regardless of the technique used for their fabrication. ${ }^{3}$ Also, Reisine et $\mathrm{al}^{4}$ reported numerous impacts of dentures on quality of life.

Patients wearing lower conventional complete denture reported inferior oral health-related quality of life, functional outcomes and satisfaction with treatment when compared with patients with fitted implant supported prostheses. ${ }^{5-11}$ However, some studies reported that patients with mandibular implant supported overdenture had similar impacts on quality of life and satisfaction with treatment when compared with conventional lower complete dentures. ${ }^{12}$ Furthermore, no differences in quality of life and satisfaction are present when conventional maxillary complete dentures were compared with maxillary implant supported dentures. ${ }^{13}$

Females with fitted conventional complete dentures reported less satisfaction with esthetics and ability to chew than males. ${ }^{14}$ Nevertheless, some studies reported no significant relationship between gender and satisfaction with complete denture treatment. ${ }^{15-20}$ However, others found that 
males were more satisfied with dentures. ${ }^{21,22}$ Awad and Feine concluded that satisfaction with conventional complete dentures depends on gender and the appearance and functionality of the denture. ${ }^{23}$ On the contrary, some studies demonstrated that older patients were less satisfied with dentures. ${ }^{22}$ However, other researcher found no such relation. ${ }^{16,18-20}$

The reason why patients are dissatisfied, when there are no objective reasons for that, could be pursued in nonmedical factors. Poljak-Guberina et al found that age, education, marital status, income state, size of the residence and regional affiliation did not have a significant influence on satisfaction of patients with the prosthesis. Also, not wearing prostheses was not linked to neuroticism. ${ }^{24}$

Some patients may be unsatisfied with their oral condition and dental treatment even if their dental status is adequate and their dental treatment is clinically successful. On the contrary, some patients are satisfied with their dentition and dental treatment even when they are unfavorable, and this could be attributed to their high level of psychogenic tolerance. ${ }^{25,26}$ Therefore, using patientcentered outcome measures could assist identification of the best treatment solution for the patient. ${ }^{27}$

Different levels of oral health status have varying impacts on people's daily living; therefore, the clinical status and psychological dimensions should be assessed whenever we assess dental needs. ${ }^{28,29}$

Satisfaction and compliance with dental status and treatment, quality of life and oral health impacts and perceptions were associated with some personality traits that might be regarded as predictors for evaluation of these issues. Examples of these traits are self-respect, selfconfidence, compliance, accommodating, quietness, extraversion, conscientiousness, agreeableness, openness, anxiety, kindliness, calmness, warmth, neuroticism and meticulousness. ${ }^{30-37}$ Less intelligent, less stable, more selfcentered, more neurotic, more careful patients were found to be less satisfied with their conventional complete denture prostheses. $^{38,39}$

Fenlon et $\mathrm{al}^{40}$ found that neurotic patients were less satisfied with complete dentures and denture use was not affected by personality traits. However, they did not use valid and reliable measures for this purpose. Also, Klages et $\mathrm{al}^{41}$ found that patient personality was behind $38.0 \%$ of functional limitation and $41.5 \%$ of physical pain. They concluded that pain sensitivity and body preoccupation might explain the subjective oral health effects of removable denture. However, they used incomprehensive questionnaires for personality assessment. Furthermore, Al Quran et $\mathrm{al}^{20}$ concluded that neuroticism influenced and predicted patients' satisfaction with dentures. Also, Moltzer et al ${ }^{42}$ concluded that patients dissatisfied with dentures were high on neuroticism, less social adequate, more rigid, had less self-esteem and more externally oriented.

On the contrary, some researchers found no relationship between denture satisfaction and personality. ${ }^{38,43,44}$ However, they used incomprehensive personality tests and paid little attention to reliability, validity and suitability of the used tests. Moreover, Lowental and Tau found no relation between denture satisfaction and personality. ${ }^{15}$

Also, Vervoorn et $\mathrm{al}^{45}$ found no relationship between denture satisfaction and personality when denture satisfaction was assessed using denture satisfaction questionnaire. However, when they used denture complaint questionnaire, they found that extraversion was related to lower denture functional complaints and feeling of a hollow face. Also, feeling bulbous face and having vague denture complaints were related to neuroticism. Nevertheless, they used the Dutch personality inventory which is incomprehensive personality test and suffer problems in validity and reliability.

Investigations of the psychological impacts following complete denture therapy are still insufficient and inconclusive.

Many researchers studied the relationship between psychological profiles and satisfaction with the dental status and treatment. Some researchers investigated the relationship between satisfaction with complete dentures and personality and concluded controversial results. Unfortunately, a lot of controversy is still existent in this regard, and the literature lacks enough valid studies of the relationship between satisfaction with complete denture prostheses and personality profiles and the impacts of this on daily living. Further investigation and careful scientificbased evidence are required to explore whether the assessment of certain psychological traits of patients can predict the impacts of complete denture prostheses on daily living and satisfaction with such treatment.

This study investigates the relationship between satisfaction with complete denture prostheses and personality profiles and the impacts of this on daily living using valid and reliable sociodental and psychological measures.

\section{MATERIALS AND METHODS}

Fifty-six patients (28 males and 28 females; mean age $53.79 \pm$ 7.762 years) with fitted upper and lower removable complete denture prostheses (CDs) constructed at AL-Quds University Dental Clinics, Jerusalem, were recruited for this 
study. The university receives patients from the whole area of West Bank, Palestinian occupied territory.

An invitation to participate in the study was extended to the patients. Each participant was given a brief explanation of the study and an informed consent was obtained from each participant before being recruited into the study. All clinical procedures were ethically approved by the deanship of research at AL-Quds University, Jerusalem.

To be included in the study, participants should have no medical disease (including mental problems and psychological disorders) that might affect their ability to understand and/or to score the questionnaires. Also, provided denture therapy should be the first set of dentures the patient ever received, in use for 3 to 6 months and clinically successful (from the dentist's point of view) throughout the entire period of the study. Patients were excluded from the study if any sign of treatment failure or denture complication and inadequacy present. Also, patients below 17 years of age were excluded from the study as they were reported to have problems in scoring the NEO-FFI test. ${ }^{46}$

The null hypothesis was that in patients treated with complete dentures, there is no relationship between psychological traits and impacts of complete denture prosthesis on patients' oral health-related quality of life and satisfaction with complete denture treatment.

One investigator conducted all clinical examinations and thoroughly assessed each patient before the study. The assessment also included patient dental and medical histories, complaints and personal information regarding name, age, gender, education, occupation, address and marital status. Intraexaminer reliability was performed on five duplicate examinations using Kappa statistics. Kappa was 1.00 indicating substantial agreement as examination criteria were very clear and simple.

All recruited patients in this study were assessed clinically by an experienced specialist prosthodontist to ensure the success of the denture treatment. The specific clinical criteria used by previous studies ${ }^{19,20}$ to assess clinical success of a complete denture were expanded and modified before being used for the purpose of this study. Therefore, the assessed criteria included assessment of appearance, retention, stability, support, speech, occlusion and health of supporting tissues.

It was decided to exclude patients with any prosthesis associated with poor extensions; poor retention, stability or support; poor speech, poor esthetics (including tooth size, shape, color, arrangement and position); infections beneath the dentures; presence of traumatic ulcers or denture hyperplasia; problems in vertical dimension, centric relation or occlusion. Also, patients with ill fitting, inadequately functioning, fractured or cracked dentures were excluded.
The dental impact on daily living questionnaire (DIDL) and its scale was used to assess patients' satisfaction with complete dentures and impacts of complete denture prostheses on daily living. ${ }^{29,32,47}$ The DIDL consists of 36 items grouped into five dimensions: comfort, appearance, pain, performance and eating restriction, and impacts for each item are scored. It measures the impact and proportional importance of each dimension (weight of the dimension) to the patient. A weight for each dimension is calculated on an individual basis by dividing the summed responses of that dimension by the total possible scale score. To construct an overall score, scores within each dimension are first calculated by multiplying the summed dimension responses by the dimension weight. Weighted dimension scores are then summed to give a DIDL score. Total score of the DIDL ranged from -1 to +1 in all sample individuals. Patients responded to each item by selecting one of the three response categories in the form of a Likert response format that includes agree, disagree or neutral.

This questionnaire was tested for Jordanian and non-Jordanian populations in previous studies and its reliability, validity, accuracy and reproducibility were authenticated. ${ }^{(29,32-37,47-49)}$ Furthermore, it was found to be an efficient tool for use by the patients and clinicians that can be completed within a relatively short time period. Its items were simple and could be easily understood and scored.

Many previous studies used different types of questionnaires and tools to rate patients' satisfaction with complete dentures. For example, the long version of oral health impact profile (OHIP) ${ }^{50}$ has adequate responsiveness, validity and reliability. Nevertheless, the large number of its items (49 items) may shrink its use in clinical research. Furthermore, using its short version (OHIP-14) decreased its reliability and validity in edentulous patients. ${ }^{51}$ Furthermore, it is complex and may confuse patients due to its psychological evaluation.

The dental impact on daily living (DIDL) test is a sociodental instrument and was used in this study because unlike other sociodental indicators, it assesses the dental impact on daily living, the relative importance that respondents attribute to each dimension and oral status. Also, the DIDL allows a respondent to indicate whether a problem is entirely internal or if it has interpersonal or social impacts. Additionally, as impacts seldom occur separately, a single impact score is given to assess total oral impact. Since, there are important links between quality of life and clinical oral status, the significant impacts should be used to assess needs. Instruments such as the OHIP do not weight dimension scores and then combine the weighted scores into a single score, as does the DIDL. 
Also, using the DIDL measure could provide a more satisfactory answer into the effects of teeth on daily living and satisfaction with the oral cavity than OHIP and OHQoLUK. ${ }^{36}$ Also, this instrument is more sensitive to the effect of variations in psychological profiles and has strong correlations to the OHIP and OHQoL-UK and thus capable of measuring the same dimensions that are measured by these instruments. Furthermore, the DIDL is suitable to use in studies that investigate the relationship between personality profiles; satisfaction with the dentition; dental impacts on daily living and oral health-related quality of life. ${ }^{36}$

On the contrary, denture satisfaction questionnaire ${ }^{38}$ is incomprehensive, rate satisfaction mainly depend on technical aspects of the denture, does not test impacts of dentures on daily living and does not weight dimension scores and then combines the weighted scores into a single score, as does the DIDL.

The visual analogue scale and categorized scales are also in use for the assessment of patients' satisfaction. However, these tools only provide an indication about satisfactory outcomes of the treatment without any mention of the effects of such therapy on various aspects of patients' quality of life and suffer similar shortcomings as above.

The NEO five factor inventory (NEO-FFI) was used to assess participants' personality profiles. ${ }^{52}$ The test consisted of 60 questions analyzing the five major personality dimensions: Neuroticism, extraversion, openness, agreeableness and conscientiousness. Each dimension was assessed using 12 questions. This test is a comprehensive method of measuring personality. ${ }^{52}$ In addition, it has a good reliability and validity structure. ${ }^{53,54}$ The NEO-FFI test was used in this study because it measures five dimensions of personality; it is simple and can be completed in a short time; it is valid, reliable and easy to use statistically. ${ }^{32,53,54}$ This questionnaire was validated for Jordanian population in previous studies and was found valid and reliable. ${ }^{34-37,48}$

Previous studies used different psychological tests to assess the relation between personality profiles and satisfaction with dentures. However, these tests suffer from some defects mainly related to comprehensiveness, reliability, validity and suitability to use.

The DIDL and NEO-FFI questionnaires were administered to the patients, and the process of completing the questionnaires was supervised by the investigator. Each patient was provided with a full explanation of the dimensions as well as the methods of scoring each questionnaire.

\section{STATISTICAL ANALYSIS}

The data were analyzed using the SPSS computer software (Statistical Package for the Social Sciences, version 11.0, SPSS Inc, Chicago, IL, USA). The association between the satisfaction scores and personality profiles was analyzed using the Pearson correlation test. The linear regression analysis was used to predict satisfaction using personality traits. For all statistical analysis, the significance level was set at $\mathrm{p} \leq 0.05$.

\section{RESULTS}

Fifty-six patients (28 males and 28 females; mean age $53.79 \pm 7.762$ years), with fitted removable complete denture treatment (CDs) were recruited for this study.

Total satisfaction scores of the DIDL questionnaire showed that 8 (14.3\%) patients were dissatisfied with their dentures and scored below 0, 28 (50\%) patients were relatively satisfied and scored between 0 and 0.69 and 20 (35.7\%) patients were totally satisfied with their teeth. The highest total satisfaction score was +0.98 , while the lowest total satisfaction score was -0.37 (mean: 0.53 ; SD: 0.39 ). Table 1 presents the satisfaction with each dimension of the DIDL questionnaire among the study population.

Table 2 presents the mean, standard deviation, range and distribution of NEO-FFI dimension scores among the study population.

Gender was found to have significant relations with DIDL and NEO-FFI scores. Females were more satisfied with appearance $(r=0.384, p=0.003)$ and less satisfied with eating $(r=-0.399, p=0.002)$ than males. Moreover, females scored higher on neuroticism $(r=0.381, p=0.004)$, and lower on extraversion and openness $(r=-0.352$, $\mathrm{p}=0.008$ and $\mathrm{r}=-0.308, \mathrm{p}=0.021$, respectively) personality domains.

Also, older patients were more satisfied with appearance $(r=0.472, p<0.0001)$ and less satisfied with oral comfort and general performance $(r=-0.318, p=0.017$ and $r=$ $-0.325, p=0.015$, respectively).

\begin{tabular}{lccc}
\multicolumn{4}{c}{ Table 1: Scores of individual satisfaction dimensions (DIDL dimensions) in the study sample $(\mathrm{n}=56)$} \\
\hline DIDL dimension & Dissatisfied (\%) & Relatively satisfied (\%) & Satisfied (\%) \\
\hline Appearance & $4(7.1)$ & $4(7.1)$ & $48(85.8)$ \\
Pain & $44(78.6)$ & $12(21.4)$ & $0(0)$ \\
Oral comfort & $44(78.6)$ & $8(14.3)$ & $4(7.1)$ \\
General performance & $44(78.6)$ & $0(0)$ & $12(21.4)$ \\
Eating and chewing & $16(28.6)$ & $4(7.1)$ & $36(64.3)$ \\
\hline
\end{tabular}




\begin{tabular}{lccccc}
\hline & \multicolumn{2}{c}{ Table 2: NEO-FFI (personality domains) scores in the study sample $(\mathrm{n}=56)$} \\
Personality domain & Mean score (SD) & Score range & \multicolumn{3}{c}{ Number of participants who scored $(n=56)$} \\
\cline { 3 - 6 } & & & Low score (\%) & Average score (\%) & High score (\%) \\
\hline Neuroticism & $21.57(6.05)$ & $12-38$ & $4(7.1 \%)$ & $32(57.1 \%)$ & $20(35.7 \%)$ \\
Extraversion & $27.86(4.51)$ & $19-36$ & $8(14.3 \%)$ & $36(64.3 \%)$ & $12(21.4 \%)$ \\
Openness & $21.07(5.39)$ & $5-27$ & $36(64.3 \%)$ & $20(35.7 \%)$ & $0(0 \%)$ \\
Agreeableness & $25.93(4.03)$ & $18-33$ & $48(85.7 \%)$ & $8(14.3 \%)$ & $0(0 \%)$ \\
Conscientiousness & $33.71(5.08)$ & $20-40$ & $12(21.4 \%)$ & $36(64.3 \%)$ & $8(14.3 \%)$ \\
\hline
\end{tabular}

\section{Correlation between DIDL and NEO-FFI scores}

Higher neuroticism scores were associated with higher levels of satisfaction with general performance ( $r=0.473$, $\mathrm{p}<0.0001)$. Furthermore, higher extraversion scores were associated with higher levels of total satisfaction $(r=0.301$, $p=0.024)$ and satisfaction with eating $(r=0.352, p=0.008)$, and lower levels of satisfaction with pain tolerance $(\mathrm{r}=$ $-0.295, p=0.027)$ and general performance $(r=-0.334$, $\mathrm{p}=0.012$ ). On the contrary, higher openness scores were associated with less satisfaction with general performance $(r=-0.464, p<0.0001)$. Also, higher agreeableness scores were associated with higher levels of satisfaction with eating $(r=0.467, p<0.0001)$. Moreover, higher conscientiousness scores were associated with less satisfaction with general performance $(r=-0.420, p=0.001)$.

\section{Regression Analysis to Predict Satisfaction using Personality Profiles}

Neuroticism was useful in predicting total satisfaction $(\mathrm{R}=0.642, \mathrm{P}=0.001)$ as well as satisfaction with general performance $(\mathrm{R}=0.658, \mathrm{P}=0.003)$. Also, extraversion was helpful in predicting total satisfaction $(\mathrm{R}=0.642, \mathrm{P}=0.001$ ) as well as satisfaction with pain tolerance $(\mathrm{R}=0.518, \mathrm{p}<$ $0.0001)$ and oral comfort $(\mathrm{R}=0.365, \mathrm{P}=0.016)$. Moreover, openness was helpful in predicting total satisfaction $(\mathrm{R}=$ $0.642, \mathrm{p}<0.0001)$ as well as satisfaction with pain tolerance $(\mathrm{R}=0.518, \mathrm{P}=0.013)$, oral comfort $(\mathrm{R}=0.365, \mathrm{P}=0.012)$, and general performance $(\mathrm{R}=0.658, \mathrm{P}=0.021)$. In addition, agreeableness was useful in predicting satisfaction with eating $(\mathrm{R}=0.639$, $\mathrm{p}=0.003)$.

Age was helpful in predicting total satisfaction $(\mathrm{R}=$ $0.642, \mathrm{p}=0.021, \mathrm{P}=0.001)$ as well as satisfaction with appearance $(\mathrm{R}=0.472, \mathrm{p}<0.0001)$ and eating $(\mathrm{R}=0.639$, $\mathrm{P}=0.009)$. While, gender was helpful in predicting satisfaction with pain tolerance $(\mathrm{R}=0.518, \mathrm{P}=0.036)$, general performance $(R=0.658, \mathrm{p}<0.0001)$ and eating ( $R$ $=0.639, \mathrm{p}<0.0001)$.

\section{DISCUSSION}

The results of this study demonstrated that a relationship could be established between psychological traits and impacts of complete denture prostheses on patients' daily living and satisfaction ratings; therefore, the null hypothesis was rejected.

Psychological factors have a recognized role in determining patient satisfaction and compliance with dental status and treatment. The evaluation of personality characteristics might be useful in predicting patient behavior and may have an effect on the provision of therapy. ${ }^{55}$

Females were more satisfied with appearance and less satisfied with eating and this could be due to that females are more aware of esthetics and quickly seek treatment for esthetic defects by denture construction that took esthetics as higher priority than function. The finding that females were less satisfied with eating than males concurs the findings of previous studies. ${ }^{14,21-23}$ However, it opposes other studies that found no relation between gender and satisfaction with complete denture. ${ }^{15-20}$

Furthermore, females were more satisfied with their appearance than males and this counters the findings of Pan et $\mathrm{al}^{14}$ who found that males were more satisfied with appearance than females. Religious and cultural backgrounds and the use of comprehensive measures with high validity and reliability might be the reason for the difference from other studies.

Females were more neurotic and less extraverted and open than males. This can be explained by that females are more self-conscious and lead more stressful life than males, and patients especially females with complete dentures had suffered some shortcomings related to their dentition that led to some effects on their quality of life and contact with people and thus they became more introvert and less open.

Older patients were more satisfied with appearance and less satisfied with general performance and oral comfort than younger patients. This could be explained by that younger patients having more critical oral demands are more concerned with respect to their appearance. Meanwhile, older patients are less demanding for appearance due to the nature of their social life and less tolerant to changes in their performance and oral comfort due to the difference in their daily living styles. Also, this might be due to agerelated changes of participants' values and expectations. ${ }^{56}$ 
The finding that older patients were less satisfied with general performance and oral comfort goes along with the findings of some previous studies that found older patients to be less satisfied with complete dentures than younger ones. ${ }^{22}$ However, it opposes the findings of other studies that reported no such relation. ${ }^{16,18-20}$ Furthermore, older patients were found to be more satisfied with esthetics than younger patients and this opposes the results of some previous studies that showed less satisfaction with complete denture among older patients. Religious and cultural backgrounds and the use of comprehensive measures with high validity and reliability might be the reason for the difference from other studies.

Although their dentures were successful from technical and functional point of view; $14.3 \%$ of the patients were dissatisfied with their denture treatment in general and $78.6 \%$ of patients were dissatisfied with pain tolerance, oral comfort and general performance associated with complete denture treatment. This could be explained by patients' psychogenic factors.

The results of this study showed that the higher the neuroticism scores the higher the satisfaction with general performance. Furthermore, the higher the extraversion scores the higher the total satisfaction and the satisfaction with eating and the lower the satisfaction with pain and general performance. On the contrary, the higher the openness scores the lower the satisfaction with general performance. Also, the higher the agreeableness scores the higher the satisfaction with eating. Moreover, the higher the conscientiousness scores the lower the satisfaction with general performance.

The above relations between personality profiles and complete denture impacts on daily living and satisfaction with complete denture treatment might be explained on the bases that the more open the patient the more they will talk about their oral-related concerns and thus the more they report negative impacts of dentures on their performance. Also, extraverted people are more outgoing and less tolerable to pain and changes in their performance as this might affect their life styles and relationships. In addition, the more agreeable the patient the more tolerant to oralrelated concerns and thus the less they report negative impacts of complete dentures. Furthermore, conscious patients are keen to perform things in perfect way and thus they report any negative impacts of denture treatment on their performance. Patients with higher neuroticism seek high standards of performance and do not allow their performance to compromise and thus seek treatment to any condition that might impact their performance, hence patients with higher neuroticism in this study showed tendency to have higher scores on general performance.
The above findings agreed with previous studies that used the DIDL and NEO-FFI instruments in other dental situations and treatments and revealed the presence of an intense role of psychological factors in determining impacts of dental treatment on daily living and shaping patients' satisfaction with dental status and treatment. ${ }^{32-37,49}$

Also, it agreed with studies on the relation between denture satisfaction and personality factors. ${ }^{20,40-42}$ However, it disagrees with other studies that reported no relation between personality profiles and denture satisfaction. ${ }^{15,38,43,44}$ This could be due to that previous studies used nonstandardized, custom-made questionnaires or personality tests that have problems with reliability, comprehensiveness, suitability to use and validity. Also, different study designs and sample size might explain such differences.

This study demonstrated that neuroticism, extraversion, openness and agreeableness personality traits were helpful in predicting complete denture impacts on daily living and satisfaction with complete denture treatment. This agrees with previous studies that demonstrated a role for personality traits in prediction of dental impacts on daily living and patient satisfaction with their dentition and dental treatment in other situations and treatments. ${ }^{20,32-35}$

To the best of our knowledge, this is the first study using NEO-FFI and DIDL instruments to investigate the relationship between personality profiles and complete denture impacts on daily living and satisfaction with complete denture treatment.

It does worth to mention that economy, cultural values, religion and social conditions might have a role in satisfaction with complete denture treatment and might modify the relation between personality and impacts of complete denture treatment on daily living and satisfaction with complete denture treatment. Further studies are required to identify the potential effects of cultural or religious factors in this regard. Also, further investigations are required on larger samples especially to evaluate the effects of other factors such as treatment costs in a private versus university settings as well as effects of being treated by general practitioners versus experienced specialists and clinicians.

This is the first study using the valid and reliable NEOFFI and DIDL instruments to investigate the relationship between personality profiles and complete denture impacts on daily living and satisfaction with complete denture treatment. Psychological profiles might be used to predict satisfactory outcomes of CD treatment. So, before starting prosthodontic treatment it might be wise to recommended evaluating the patients' personality profiles and if certain profiles are detected then healthcare professionals can pay more attention to patients' expectations and response to the offered treatment. This measure might avoid unnecessary 
costs and save efforts and time of both the dentists and the patient.

\section{CONCLUSION}

Within the limitation of this study, it was concluded that edentulous patients might be dissatisfied with complete denture treatment and experience negative impacts of complete dentures on their daily living even if the dentures were clinically and technically adequate from the dentist's point of view.

It is possible that some psychological aspects (e.g. neuroticism, extraversion, openness and agreeableness) might play a role and explain complete denture impacts on daily living and patients' satisfaction with their oral status and complete denture treatment. They might also provide valuable information for the prediction of satisfactory outcomes before commencing complete denture treatment.

\section{REFERENCES}

1. Carlsson GE, Omar R. The future of complete dentures in oral rehabilitation. A critical review. J Oral Rehabil 2010;37:79-156.

2. Veyrune JL, Tubert-Jeannin S, Dutheil C, Riordan PJ. Impact of new prostheses on the oral health related quality of life of edentulous patients. Gerodontology 2005;22:3-9.

3. Ellis JS, Pelekis ND, Thomason JM. Conventional rehabilitation of edentulous patients: The impact on oral health-related quality of life and patient satisfaction. J Prosthodont 2007;16:37-42.

4. Reisine ST, Fertig J, Weber J, Leder S. Impact of dental conditions on patients' quality of life. Community Dent Oral Epidemiol 1989;17:7-10.

5. Berretin-Felix G, Machado WM, Genaro KF, Nary Filho H. Effects of mandibular fixed implant-supported prostheses on masticatory and swallowing functions in completely edentulous elderly individuals. Int J Oral Maxillofac Implants 2009;24: 110-17.

6. Berretin-Felix G, Nary Filho H, Padovani CR, Machado WM. A longitudinal study of quality of life of elderly with mandibular implant-supported fixed prostheses. Clin Oral Implants Res 2008;19:704-08.

7. Turkyilmaz I, Company AM, McGlumphy EA. Should edentulous patients be constrained to removable complete dentures? The use of dental implants to improve the quality of life for edentulous patients. Gerodontology 2010;27:3-10.

8. Emami E, Heydecke G, Rompré PH, de Grandmont P, Feine JS. Impact of implant support for mandibular dentures on satisfaction, oral and general health-related quality of life: A meta-analysis of randomized-controlled trials. Clin Oral Implants Res 2009;20:533-44.

9. Roumanas ED. The social solution-denture esthetics, phonetics, and function. J Prosthodont 2009;18:112-15.

10. Hobkirk JA, Abdel-Latif HH, Howlett J, Welfare R, Moles DR. Prosthetic treatment time and satisfaction of edentulous patients treated with conventional or implant-stabilized complete mandibular dentures: A case-control study (part 2). Int J Prosthodont 2009;22:13-19.

11. Rismanchian M, Bajoghli F, Mostajeran Z, Fazel A, Eshkevari P. Effect of implants on maximum bite force in edentulous patients. J Oral Implantol 2009;35:196-200.
12. Assunção WG, Zardo GG, Delben JA, Barão VA. Comparing the efficacy of mandibular implant-retained overdentures and conventional dentures among elderly edentulous patients: Satisfaction and quality of life. Gerodontology 2007;24: 235-38.

13. Thomason JM, Heydecke G, Feine JS, Ellis JS. How do patients perceive the benefit of reconstructive dentistry with regard to oral health-related quality of life and patient satisfaction? A systematic review. Clin Oral Implants Res 2007;18(Suppl) 3:168-88

14. Pan S, Awad M, Thomason JM, Dufresne E, Kobayashi T, Kimoto S, et al. Sex differences in denture satisfaction. J Dent 2008;36:301-08.

15. Lowental U, Tau S. Effects of ethnic origin, age and bereavement on complete denture patients. J Prosthet Dent 1980;44:133-36.

16. Weinstein M, Schuchman J, Lieberman J, Rosen P. Age and denture experience as determinants in patient denture satisfaction. J Prosthet Dent 1988;59:327-29.

17. Beck CB, Bates JF, Basker RM, Gutteridge DL, Harrison A. A survey of the dissatisfied denture patient. Eur J Prosthodont Restor Dent 1993;2:73-78.

18. Brunello DL, Mandikos MN. Construction faults, age, gender, and relative medical health: Factors associated with complaints in complete denture patients. J Prosthet Dent 1998;79:545-54.

19. Al Quran FA. Factors influencing the acceptance of complete dentures. Belfast, Northern Ireland: Queen’s University Belfast, $\mathrm{PhD}$ thesis 1999.

20. Al Quran F, Clifford T, Cooper C, Lamey PJ. Influence of psychological factors on the acceptance of complete dentures. Gerodontology 2001;18:35-40.

21. Silverman S, Silverman SI, Silverman B, Garfinkel L. Self image and its relation to denture acceptance. J Prosthet Dent 1976;35:131-41.

22. Powter G, Cleaton-Jones P. Quantitative assessment of some factors governing complete denture success. J Dent Assoc S Afr 1980;35:5-8.

23. Awad MA, Feine JS. Measuring patient satisfaction with mandibular prostheses. Community Dent Oral Epidemiol 1998;26:400-05.

24. Poljak-Guberina R, Culig B, Zivković O, Catović A, Kuzmanović D, Muljacić A. Patients’ satisfaction with prosthetic devices. Coll Antropol 2005;29:615-21.

25. Branchi R, Boddi V, Corti D, Hardoy MJ. Can a prosthesis cause psychological disturbances? J Oral Rehabil 2001;28:1133-38.

26. Allen PF. Assessment of oral health related quality of life. Health Qual Life Outcomes 2003;1:40.

27. Strassburger C, Kerschbaum T, Heydecke G. Influence of implant and conventional prostheses on satisfaction and quality of life: A literature review (Part 2). Qualitative analysis and evaluation of the studies. Int J Prosthodont 2006;19:339-48.

28. Cushing AM, Sheiham A, Maizels J. Developing sociodental indicators: The social impact of dental disease. Community Dental Health 1986;3:3-17.

29. Leao A, Sheiham A. Relation between clinical dental status and subjective impacts on daily living. J Dent Res 1995;74: 1408-13.

30. Mehra T, Nanda RS, Sinha PK. Orthodontists' assessment and management of patient compliance. Angle Orthod 1998;68: $115-22$.

31. Dong H, Bogg L, Rehnberg C, Diwan V. Health financing policies. Providers' opinions and prescribing behavior in rural China. Int J Technol Assess Health Care 1999;15:686-98. 
32. AL-Omiri MK. Tooth wear impact on daily living. Belfast, Northern Ireland: Queen's University Belfast, PhD thesis 2002.

33. AL-Omiri MK, Lamey P-J, Cooper C, Clifford T. Relationship between personality and satisfaction with the dentition in tooth wear patients. Eur J Prosthodont Restor Dent 2006;14:179-84.

34. Al-Omiri MK, Abu Alhaija ES. Factors affecting patient satisfaction after orthodontic treatment. Angle Orthod 2006;76:422-31.

35. Abu Hantash RO, AL-Omiri MK, AL-Wahadni AM. Psychological impact on implant patients' oral health related quality of life. Clin Oral Implants Res 2006;17:116-23.

36. Karasneh J, AL-Omiri MK, Al-Hamad K, Al Quran F. Relationship between patients' oral health-related quality of life, satisfaction with dentition and personality profiles. J Contemp Dent Prac [Internet] 2009;10:49-56.

37. AL-Omiri MK, Karasneh J. Relationship between oral healthrelated quality of life, satisfaction and personality in patients with prosthetic rehabilitations. J Prosthodont 2010;19:2-9.

38. Guckes AD, Smith DE, Swoope CC. Counseling and related factors influencing satisfaction with dentures. J Prosth Dent 1978;39:259-67.

39. Reeve P, Stafford GD, Watson C, Hopkins R. The use of Cattell's personality profile in patients who have had preprosthetic surgery. J Dent 1982;10:121-30.

40. Fenlon MR, Sherriff M, Newton JT. The influence of personality on patients' satisfaction with existing and new complete dentures. J Dent 2007;35:744-48.

41. Klages U, Esch M, Wehrbein H. Oral health impact in patients wearing removable prostheses: Relations to somatization, pain sensitivity, and body consciousness. Int J Prosthodont 2005;18:106-11.

42. Moltzer G, Van der Meulen MJ, Verheij H. Psychological characteristics of dissatisfied denture patients. Community Dent Oral Epidemiol 1996;24:52-55.

43. Smith H. Measurement of personality traits and their relation to patient satisfaction with complete dentures. J Prosthet Dent 1976;35:492-503.

44. van Waas MA. The influence of psychologic factors on patient satisfaction with complete dentures. J Prosthet Dent 1990;63:545-48.

45. Vervoorn JM, Duinkerke AS, Luteijn F, van de Poel AC. Relative importance of psychologic factors in denture satisfaction. Community Dent Oral Epidemiol 1991;19:45-47.

46. De Fruyt F, Mervielde I, Hoekstra HA, Rolland JP. Assessing adolescents' personality with the NEO PI-R. Assessment 2000;7:329-45.

47. Leao A. The development of measures of dental impacts on daily living. London: London University, PhD thesis 1993.

48. Abu Hantash RO. Personality and satisfaction with dental implants. Irbid, Jordan: Jordan University of Science and Technology, MSc Thesis 2004.

49. AL-Omiri MK, Karasneh J, Lynch E, Lamey PJ, Clifford C. Impacts of missing upper anterior teeth on daily living. Int Dent J 2009;59:127-32.

50. Slade GD, Spencer AJ. Development and evaluation of the oral health impact profile. Community Dental Health 1994;11:3-11.
51. Awad M, Al-Shamrany M, Locker D, Allen F, Feine J. Effect of reducing the number of items of the oral health impact profile on responsiveness, validity and reliability in edentulous populations. Community Dent Oral Epidemiol 2008;36: 12-20.

52. Costa PT Jr, McCrae RR. Revised NEO personality inventory (NEO PI-R) and NEO five-factor inventory (NEO-FFI) professional manual. PAR Psychological Assessment Resources Inc, Florida, USA 1992.

53. Kline P. The Handbook of Psychological Testing (2nd ed). London: Routledge 2000.

54. Saucier G. Replicable item-cluster subcomponents in the NEO five-factor inventory. J Pers Assess 1998;70:263-76.

55. Piedmont RL. The revised NEO personality inventory: Clinical and research applications. New York: Plenum Press 1998.

56. Astrøm AN, Haugejorden O, Skaret E, Trovik TA, Klock KS. Oral impacts on daily performance in Norwegian adults: The influence of age, number of missing teeth, and sociodemographic factors. Eur J Oral Sci 2006;114:115-21.

\section{ABOUT THE AUTHORS}

\section{Raed O Abu Hantash}

Assistant Professor and Consultant, Head, Department of Prosthodontics, AL-Quds University, Jerusalem, Israel

\section{Mahmoud K AL-Omiri}

Associate Professor and Consultant, Head, Department of Fixed and Removable Prosthodontics and Implants, Consultant, Department of Oral and Maxillofacial Surgery and Oral Medicine, The University of Jordan, Amman, Jordan

\section{Mohammad Abu Yunis}

Assistant Professor and Consultant, Department of Oral and Maxillofacial Surgery, Head, Faculty of Dentistry, AL-Quds University, Jerusalem, Israel

\section{Najla Dar-Odeh}

Associate Professor and Consultant, Department of Oral Medicine Surgery and Periodontology, The University of Jordan Amman, Jordan

\section{Edward Lynch}

Head, Department of Dental Education and Research, Professor and Consultant of Restorative Dentistry and Gerodontology, Warwick Dentistry, Warwick Medical School, United Kingdom

\section{CORRESPONDING AUTHOR}

Mahmoud K AL-Omiri, Head, Department of Prosthodontics, Faculty of Dentistry, University of Jordan, Amman 11942, Jordan, Phone: 0096279 5571629, e-mail: alomirim@yahoo.co.uk 